\title{
Specific requirement of DRB4, a dsRNA-binding protein, for the in vitro dsRNA-cleaving activity of Arabidopsis Dicer-like 4
}

\author{
AKIHITO FUKUDOME, AKIHIRO KANAYA, MAI EGAMI, YUKIHIRO NAKAZAWA, ${ }^{1}$ AKIHIRO HIRAGURI, ${ }^{2}$ \\ HIROMITSU MORIYAMA, and TOSHIYUKI FUKUHARA \\ Department of Applied Biological Sciences, Tokyo University of Agriculture and Technology, 3-5-8 Saiwaicho, Fuchu, Tokyo 183-8509, Japan
}

\begin{abstract}
Arabidopsis thaliana Dicer-like 4 (DCL4) produces 21-nt small interfering RNAs from both endogenous and exogenous doublestranded RNAs (dsRNAs), and it interacts with DRB4, a dsRNA-binding protein, in vivo and in vitro. However, the role of DRB4 in DCL4 activity remains unclear because the dsRNA-cleaving activity of DCL4 has not been characterized biochemically. In this study, we biochemically characterize DCL4's Dicer activity and establish that DRB4 is required for this activity in vitro. Crude extracts from Arabidopsis seedlings cleave long dsRNAs into 21-nt small RNAs in a DCL4/DRB4-dependent manner. Immunoaffinity-purified DCL4 complexes produce 21-nt small RNAs from long dsRNA, and these complexes have biochemical properties similar to those of known Dicer family proteins. The DCL4 complexes purified from drb4-1 do not cleave dsRNA, and the addition of recombinant DRB4 to drb4-1 complexes specifically recovers the 21-nt small RNA generation. These results reveal that DCL4 requires DRB4 to cleave long dsRNA into 21-nt small RNAs in vitro. Amino acid substitutions in conserved dsRNA-binding domains (dsRBDs) of DRB4 impair three activities: binding to dsRNA, interacting with DCL4, and facilitating DCL4 activity. These observations indicate that the dsRBDs are critical for DRB4 function. Our biochemical approach and observations clearly show that DRB4 is specifically required for DCL4 activity in vitro.
\end{abstract}

Keywords: DRB4; DCL4; Dicer activity; dsRNA-binding protein; dsRNA

\section{INTRODUCTION}

RNAi or RNA silencing pathways are widely conserved among eukaryotes, and specific interactions between Dicer and double-stranded RNA (dsRNA)-binding proteins (dsRBP) play pivotal roles in producing small RNAs. For instance, Drosophila Dicer-1 and Dicer-2 interact with the dsRBPs, loquacious and R2D2, respectively (Liu et al. 2003; Forstemann et al. 2005); Caenorhabditis elegans DCR-1 associates with RDE-4 (Tabara et al. 2002); and human Dicer interacts with trans-activation response RNA-binding protein (hTRBP) and/or PACT (Chendrimada et al. 2005; Haase et al. 2005;

\footnotetext{
${ }^{1}$ Present address: National Institute for Agro-Environmental Sciences, 3-1-3 Kannondai, Tsukuba 305-8604, Japan.

${ }^{2}$ Present address: Research Team for Vectorborne Diseases, National Agricultural Research Center, Tsukuba, Ibaraki 305-8666, Japan.

Reprint requests to: Toshiyuki Fukuhara, Department of Applied Biological Sciences, Tokyo University of Agriculture and Technology, 3-5-8 Saiwaicho, Fuchu, Tokyo 183-8509, Japan; e-mail: fuku@cc.tuat. ac.jp; fax: 81423675627.

Article published online ahead of print. Article and publication date are at http://www.rnajournal.org/cgi/doi/10.1261/rna.2455411.
}

Lee et al. 2006). In those interactions, the functions of dsRBPs vary, ranging from facilitating the production of small RNAs to promoting assembly of RNA-induced silencing complex (RISC). To understand the nature of any particular Dicer activity and function, it is important to understand the role(s) of the dsRBP associating with it.

Arabidopsis thaliana has four Dicer-like proteins (DCL1-4) and five dsRNA-binding proteins (DRB1/HYL1, DRB2-5) that are orthologous to the animal dsRBPs. Genetic and biochemical studies have revealed that there are at least two specific interactions between DCLs and DRBs. DCL1 specifically interacts with DRB1/HYL1 and produces micro-RNAs (miRNAs) from endogenous precursors with hairpin-loop structure (Han et al. 2004; Kurihara and Watanabe 2004; Vazquez et al. 2004a; Hiraguri et al. 2005). In this interaction, it has been biochemically demonstrated that DRB1/HYL1 is required for the accurate processing of miRNA precursors into mature miRNAs by DCL1 (Dong et al. 2008). In a distinct process, DCL4 interacts with DRB4, generates 21-nt small interfering RNAs (siRNAs) from exogenous or endogenous long dsRNAs, and silences target gene expression via 
post-transcriptional gene silencing. Genetic studies have revealed that DCL4 mediates two distinct pathways: transacting siRNA (tasiRNA) and viral siRNAs (vsiRNA). In the tasiRNA pathway, RNAs transcribed from TAS genes are cleaved at a certain site by an miRNA-loaded RISC (Xie et al. 2005; Yoshikawa et al. 2005). These cleaved fragments serve as templates for the RNA-dependent RNA polymerase 6 (RDR6) and SGS3 complex, resulting in dsRNA formation (Peragine et al. 2004; Vazquez et al. 2004b; Kumakura et al. 2009). Then DCL4 cleaves the dsRNAs into 21-nt tasiRNAs, regulating target gene expressions in a trans-acting manner (Xie et al. 2005; Yoshikawa et al. 2005). DCL4 also participates in the defense against viruses, converting virus-derived dsRNAs into 21-nt vsiRNAs and suppressing viral proliferation (Blevins et al. 2006; Deleris et al. 2006). A similar response is induced when artificial transgenes that encode a hairpin-loop RNA are expressed in cells (Dunoyer et al. 2005; Fusaro et al. 2006).

Although it has been demonstrated genetically and biochemically that DRB4 specifically interacts with DCL4 in vitro and in vivo (Hiraguri et al. 2005; Nakazawa et al. 2007), the role of DRB4 in the DCL4-mediated generation of 21-nt small RNAs remains unclear because a drb4-1-null mutation shows different effects on the different pathways. In drb4-1 plants, TAS2 tasiRNA accumulation seems unchanged (Adenot et al. 2006; Nakazawa et al. 2007), the accumulation of TAS1 and TAS3 tasiRNAs is slightly reduced, accumulation of 21 -nt siRNAs derived from viral dsRNAs or exogenous transgenes is abolished, and 22-nt and 24-nt siRNAs produced by DCL2 or DCL3 increase (Dunoyer et al. 2007; Curtin et al. 2008). Moreover, no in vitro biochemical characterization of DCL4 Dicer activity, including any characterization of DRB4's role, has been reported.

In this study, we demonstrated that DCL4 generated 21-nt small RNAs in vitro and that DRB4 was required for this activity. Immunoaffinity-purified DCL4 complexes produced 21-nt small RNAs from long dsRNAs. DCL4 complexes purified from drb4-1 did not cleave dsRNA, but the addition of recombinant DRB4 specifically recovered this activity. Site-directed mutagenesis experiments revealed that the dsRNA-binding domains (dsRBDs) in DRB4 were essential to its ability to bind dsRNA, interact with DCL4, and facilitate Dicer activity.

\section{RESULTS}

\section{An Arabidopsis crude extract cleaves long dsRNA into 21-nt small RNAs in a DCL4/DRB4-dependent manner}

There has been no report that demonstrates that DCL4 cleaves dsRNA in vitro; therefore, we initially attempted to determine whether DCL4 in crude extracts from Arabidopsis seedlings cleaved dsRNA. A previous study showed that crude extracts from Arabidopsis inflorescence tissues produce 21-nt and 24-nt small RNAs from long dsRNA in vitro (Qi et al. 2005). We performed the same experiment using crude extracts from 2-wk-old Arabidopsis seedlings. Crude extracts from wild-type (WT) plants incubated with 500-bp dsRNA as a substrate produced 21-nt and 24-nt small RNAs, but extract from a $d c l 4-2$ mutant under the same experimental conditions generated only 24-nt small RNAs, suggesting that the generation of 21-nt small RNAs from long dsRNA was dependent on DCL4 (Fig. 1, lanes 2,4). The small RNAs produced by WT extract were confirmed to be $21 \mathrm{nt}$ using the products of recombinant human Dicer (Fig. 1, lane 6), which were separately compared to 21-nt synthetic oligoribonucleotide markers (data not shown). DCL1 is also known to produce 21-nt small RNAs from long dsRNA in vitro (Qi et al. 2005). However, we could not detect DCL1 activity in this assay since a single mutation of DCL4 (dcl4-2) abolished the 21-nt small RNA-generating activity. Consistent with previous genetic and biochemical studies (Xie et al. 2004; Qi et al. 2005), the activity which produced small RNAs of $\sim 24 \mathrm{nt}$ in length was abolished in $d c l 3-1$ extract (Fig. 1, lane 3), indicating that DCL3 is responsible for 24-nt small RNA-generating activity. Interestingly, extract from $d r b 4-1$ seedlings, like extract from dcl4-2 seedlings, did not generate 21-nt small RNAs (Fig. 1, lane 5). This result led us to propose that DRB4 plays an essential role in dsRNA cleavage and production of 21-nt small RNAs by DCL4. In addition, genetic studies have reported that the accumulation of 22-nt and 24-nt exogenous siRNAs due to DCL2 or DCL3 increases in a drb4-1 background (Dunoyer

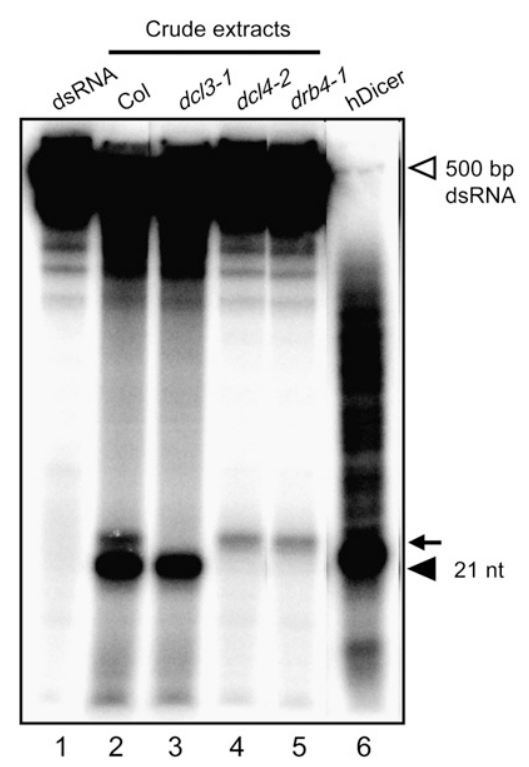

FIGURE 1. Detection of dsRNA-cleaving activity of DCL4 in Arabidopsis crude extracts. ${ }^{32}$ P-labeled 500-bp dsRNAs were incubated with Arabidopsis wild-type (Colombia; Col), dcl3-1, $d c l 4-2$, or drb4-1 crude extract for $2 \mathrm{~h}$ at $27^{\circ} \mathrm{C}$. The cleavage products were analyzed on $15 \%$ denaturing PAGE with $8 \mathrm{M}$ urea. A recombinant human Dicer fragment (hDicer; TaKaRa) was used as a cleavage control to generate size markers for 21-nt small RNA. (White arrowhead) The 500-bp dsRNA substrates; (black arrowhead) 21-nt; (black arrow) 24-nt small RNAs. 
et al. 2007; Curtin et al. 2008), but the activity that produces small RNAs of $\sim 24$ nt was not enhanced in the drb4-1 crude extract. (Fig. 1, lane 5).

\section{Complexes isolated by the anti-DRB4 antibody show DCL4 Dicer activity in vitro}

To further characterize DCL4 activity, we tried to purify DCL4 from crude extracts by coimmunoprecipitation (Co-IP) using an anti-DRB4 antibody. Immunoprecipitates derived from WT (Columbia, Col) extracts treated with anti-DRB4 antibody (DRB4 complexes) were expected to contain a DRB4 antigen and its interacting partner, DCL4 (Hiraguri et al. 2005; Nakazawa et al. 2007). Western blots confirmed that DCL4 was present in anti-DRB4 immunoprecipitates from WT extracts (Fig. 2A, lane 2). Moreover, an in vitro dsRNA-cleaving assay using those immunoprecipitates showed that DRB4 complexes precipitated from WT extracts cleaved 500-bp dsRNA into 21-nt small RNAs in vitro (Fig. 2A, lane 2). DRB4 complexes immunoprecipitated from dcl4-2 extracts, which lack intact DCL4, did not exhibit DCL4 dicing activity, and DCL4 protein was not detected on Western blots of these immunoprecipitates (Fig. 2A, lane 3). DRB4 immunoprecipitates from $d r b 4-1$ extracts did not exhibit DCL4 dicer activity in the dsRNAcleaving assay or DCL4 signal on Western blots (Fig. 2A, lane 4). We also examined the biochemical properties of this DCL4 activity. The cleavage was inhibited by high $\mathrm{NaCl}$ concentration (200-300 mM) (Fig. 2B,D) and required ATP or GTP and $\mathrm{Mg}^{2+}$ (Fig. 2C,E). These properties were similar to those of known Dicer family proteins, especially Arabidopsis DCL1 (Dong et al. 2008). Using Co-IP with anti-DRB4 antibody, we successfully purified DCL4 protein and Dicer activity from crude extracts as a complex with DRB4 in vitro.
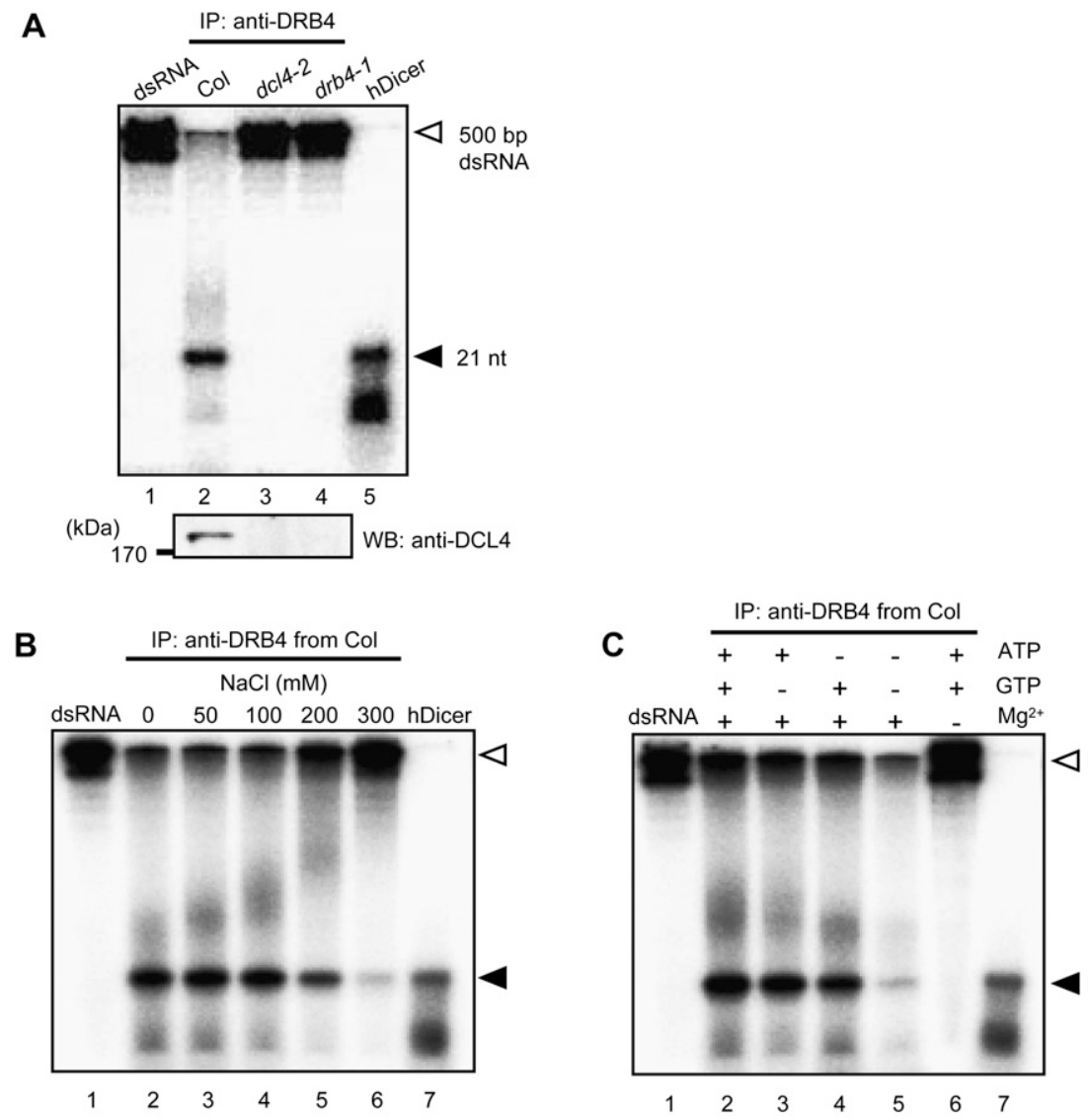

D

E

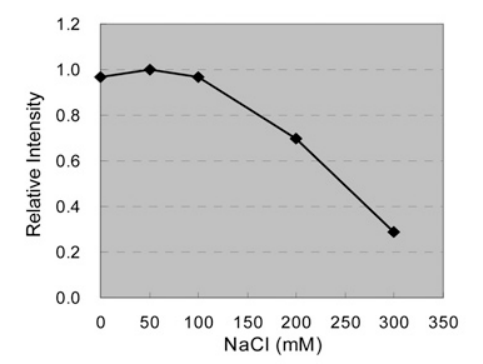

FIGURE 2. Biochemical characterization of in vitro dsRNA-cleaving activity of complexes immunoprecipitated with anti-DRB4 antibody (DRB4 complexes). (A) The dsRNA-cleaving activities of DRB4 complexes purified from WT (Col), $d c l 4-2$, and $d r b 4-1$ crude extract by the anti-DRB4 antibody were assayed. The existence of DCL4 in each complex was confirmed by Western blotting with the anti-DCL4 antibody (lower panel). (B) The effects of $\mathrm{NaCl}$ concentrations (0-300 mM) on the dsRNA-cleaving activity of DRB4 complexes. $(C)$ DRB4 complexes required $5 \mathrm{mM}$ ATP, $5 \mathrm{mM}$ GTP, and $4 \mathrm{mM} \mathrm{Mg}^{2+}$ for the dsRNA-cleaving activity. When both ATP and GTP were present in the reaction mixture (lanes 2,6), $1 \mathrm{mM}$ GTP was used instead. $(D)$ Quantification of 21-nt small RNA products shown in B. Standard condition (lane 3 in $B$ ) was set at the arbitrary relative unit "1.0." (E) Quantification of 21-nt small RNA products shown in C. Standard condition (lane 2 in $C$ ) was set at the arbitrary relative unit "1.0." (White arrowheads) The 500-bp dsRNA substrates; (black arrowheads) the 21-nt small RNA products.

\section{The DCL4 complexes from drb4-1 do not produce small RNAs in vitro}

The extracts from $d r b 4-1$ did not produce 21-nt small RNAs at all (Fig. 1), suggesting that DRB4 played an essential role in
dsRNA cleavage by DCL4. To assess the effects of DRB4 on the dsRNA-cleaving activity of DCL4 complexes directly, we performed Co-IP using anti-DCL4 antibody to obtain complexes containing DCL4. Resulting immunoprecipitates (DCL4 complexes) from WT extracts were expected to 
contain DRB4 as a complex with DCL4, but those from dcl4-2 extracts were expected not to contain specific proteins because the DCL4 antigen was absent from the extracts (Nakazawa et al. 2007). As expected, DCL4 complexes from WT generated 21-nt small RNAs from 500-bp dsRNA, and those from $d c l 4-2$ did not (Fig. 3A, lanes 1,3). We also characterized biochemical properties of this cleavage activity as we had for the DRB4 complexes. The DCL4 complexes, like the DRB4 complexes, cleaved dsRNA in an ATP/GTP/ $\mathrm{Mg}^{2+}$ dependent manner, and this cleavage was inhibited by high $\mathrm{NaCl}$ concentration (Fig. 3B). When compared directly, the biochemical properties of the DRB4 complexes precipitated by the anti-DRB4 antibody were similar to those of the DCL4 complexes precipitated by the anti-DCL4 antibody (Fig. 3C,D). This comparison of the biochemical properties confirmed that both complexes had the same DCL4 activity in vitro. Consistent with the results obtained using crude extracts (Fig. 1), DCL4 complexes precipitated from $d r b 4-1$ extracts, which lack DRB4, did not cleave the dsRNA substrate into 21-nt small RNAs (Fig. 3A, lane 2). This result

A

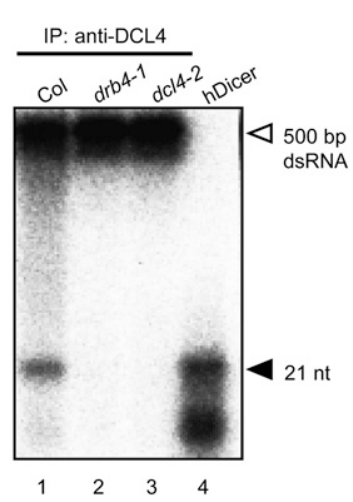

C

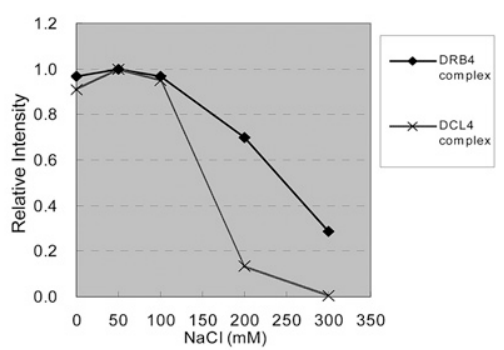

FIGURE 3. Biochemical characterization of in vitro dsRNA-cleaving activity of complexes immunoprecipitated with anti-DCL4 antibody (DCL4 complexes). (A) The dsRNA-cleaving activities of DCL4 complexes purified from WT (Col), $d r b 4-1$, and $d c l 4-2$ crude extracts by the anti-DCL4 antibody were assayed. $(B)$ The effects of $\mathrm{NaCl}$ concentrations and the requirement of $5 \mathrm{mM}$ ATP, $5 \mathrm{mM}$ GTP, or $4 \mathrm{mM} \mathrm{Mg}^{2+}$ on the dsRNA-cleaving activity of DCL4 complexes. When both ATP and GTP were present in the reaction mixture (lanes 2-7,11), $1 \mathrm{mM}$ GTP was used instead. $(C, D)$ Comparison of the biochemical properties between DRB4 complexes (Fig. 2) and DCL4 complexes. (C) The 21-nt small RNA products shown in $B$ (lanes 2-6) are quantified as described in Figure 2D,E, then plotted on the same graph in Figure 2D. $(D)$ The 21-nt small RNA products shown in $B$ (lanes 7-11) are quantified as described in Figure 2D,E, then plotted on the same graph in Figure 2E. (White arrowheads) The 500-bp dsRNA substrates; (black arrowheads) the 21-nt small RNA products. indicated that DCL4 required a dsRBP partner, specifically DRB4, to cleave dsRNA into 21-nt small RNAs.

\section{Recombinant DRB4, but not other DRB family proteins, enables the DCL4 complexes from $d r b 4-1$ to produce 21-nt small RNAs}

Previously, we reported that recombinant DRB4 (reDRB4) binds to the C-terminal half of DCL4 in vitro (Hiraguri et al. 2005). We examined whether reDRB4 enabled the DCL4 complexes isolated from $d r b 4-1$ to produce $21-$ nt small RNAs in vitro. We prepared full-length reDRB4 as a GST-fusion protein (Fig. 4A). After the GST-tag was removed by PreScission Protease, 0.1 to $312.5 \mathrm{ng}$ of reDRB4 protein was added to the dsRNA-cleaving assay using the DCL4 complexes precipitated from $d r b 4-1$ extracts ( $d r b 4$-DCL4 complexes). The addition of reDRB4 to the $d r b 4$-DCL4 complexes resulted in the production of 21-nt small RNAs, demonstrating that reDRB4 rescued Dicer activity in the DCL4 complexes precipitated from DRB4-deficient extracts (Fig. 4B). Maximum Dicer activity in this assay occurred with the addition of 12.5 to $62.5 \mathrm{ng}$ of reDRB4, and much less small RNA was detected with $312.5 \mathrm{ng}$ of reDRB4, suggesting that an excess of reDRB4 inhibited DCL4 activity (Fig. 4C). Similar observation has been reported previously for dsRBP RDE-4 from Caenorhabditis elegans, using rde-4 mutant cell extracts and recombinant RDE-4 protein (Parker et al. 2006).

To test whether this rescue was specific to reDRB4, we prepared other DRB family proteins from Escherichia coli (reDRB1/ HYL1, reDRB2, reDRB3, and reDRB5) (Fig. 4A). To check for nuclease contaminants in the DRB protein preparations, we carried out the dsRNA-cleaving assay using only DRB protein preparations (Fig. 4D, lanes 1-5). Protein preparations of reDRB1/HYL1, reDRB2, reDRB3, and reDRB4 did not contain RNase activity (Fig. 4D, lanes 1-5); however, the reDRB5 preparation did exhibit RNase activity, possibly due to contaminated nuclease from E. coli (data not shown). Thus, we did not use reDRB5 in further assays. The addition of reDRB1/HYL1, reDRB2, or reDRB3 did not improve the dsRNA cleavage by $d r b 4$-DCL4 complexes, and only DRB4 rescued Dicer activity of the drb4-DCL4 complexes (Fig. 4D, lane 11). Consistent with the results with drb4DCL4 complexes, the addition of $50 \mathrm{ng}$ of recombinant DRB4 into drb4-1 crude extract also rescued DCL4 activity, which 
A

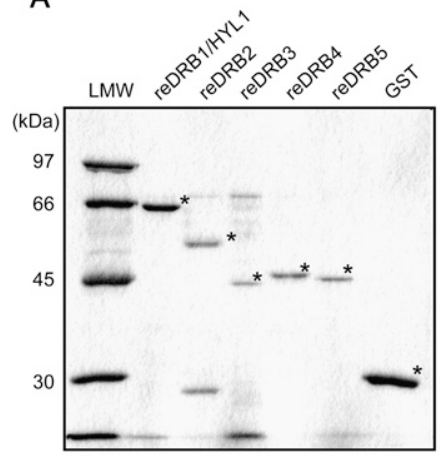

C

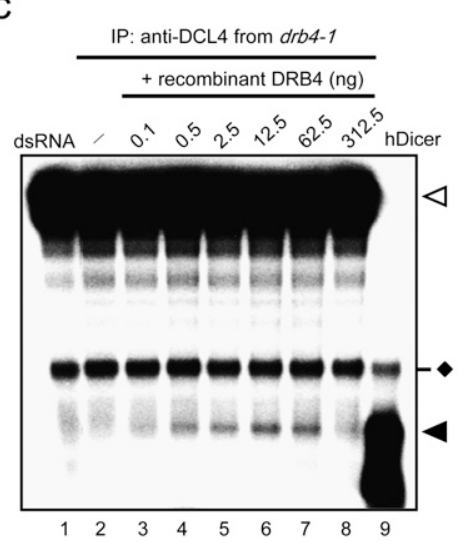

B

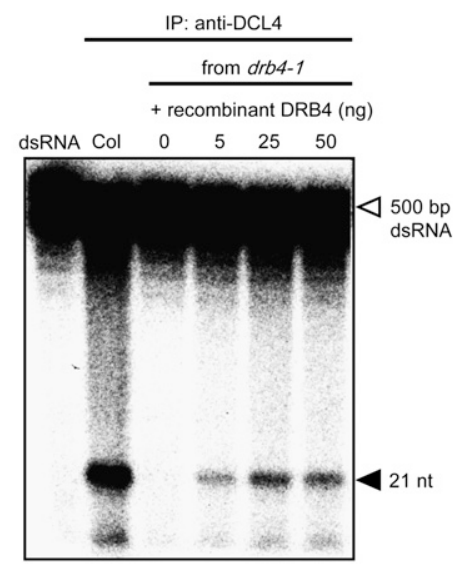

D

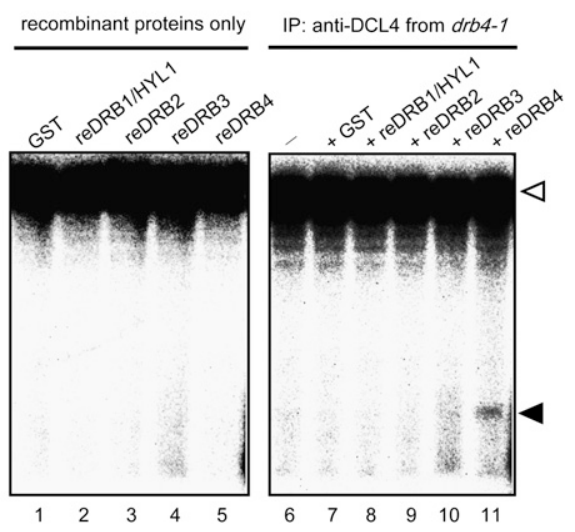

FIGURE 4. Effects of recombinant DRB proteins on the dsRNA-cleaving activity of DCL4 complexes. (A) Purified recombinant GST, DRB1/HYL1, DRB2, DRB3, DRB4, and DRB5 proteins were fractionated by $8 \%$ SDS-PAGE, and then stained by CBB. Asterisks indicate the protein of interest. $(B-D)$ Immunoprecipitate $(15 \mu \mathrm{L})$ purified from $d r b 4-1$ by the anti-DCL4 antibody ( $d r b 4$-DCL4 complexes) was incubated with recombinant proteins for $30 \mathrm{~min}$ at $4^{\circ} \mathrm{C}$. The dsRNA-cleaving activity of each complex was assayed. (B) The effect of recombinant DRB4 on the dsRNA-cleaving activity of $d r b 4$-DCL4 complexes. About 5 to $50 \mathrm{ng}$ of recombinant DRB4 protein was used. $(C)$ The same as $B$ using $\sim 0.1-312.5 \mathrm{ng}$ of recombinant DRB4 proteins. $(D)$ The effect of each DRB family protein on the dsRNA-cleaving activity of drb4-DCL4 complexes. Twenty-five nanograms of each protein was used. (White arrowheads) The 500-bp dsRNA substrates; (black arrowheads) the 21-nt small RNA products. (Diamond) Short RNA fragments in dsRNA substrates (see Materials and Methods).

generates 21-nt small RNAs (Supplemental Fig. S1, lane 4). These results clearly confirm that DCL4 interacts specifically with DRB4 in vitro and indicate that DCL4 required the dsRBP DRB4 to cleave long dsRNA into 21-nt small RNAs. Although not all DRB family proteins were examined here, the result from $d r b 4-1$ crude extract, which did not cleave dsRNA into 21-nt small RNAs (Fig. 1, lane 5), also supports the hypothesis that DRB4, alone among the DRB proteins, interacts with DCL4 to generate 21-nt small RNAs.

\section{Both activities of dsRNA-binding and protein-protein interaction are essential for DRB4}

In our previous in vitro studies, no dsRNA-binding activity was detected in the C-terminal half of DCL4, which includes two putative dsRBDs (Hiraguri et al. 2005). Here we have shown that the DCL4 complexes without the dsRBP partner DRB4 did not cleave dsRNA in vitro. This observation led us to speculate that DCL4 depended on the dsRNA-binding activity of DRB4 to produce small RNA. We introduced several amino acid substitutions into the dsRBDs of DRB4 to obtain mutant DRB4 proteins that could not bind to dsRNAs. We targeted two amino acids, which are well conserved among various dsRBPs from animals to plants. Histidine (H) at position 32 (dsRBD1, region2) and lysine (K) at position 133 (dsRBD2, region3) in DRB4 are analogous to H141 and K163, respectively, on the Xenopus laevis dsRBP Xlrbpa (Fig. $5 A)$. Structural studies have reported that these residues in Xlrbpa form hydrogen bonds directly with 2 '-OH or the phosphodiester backbone of dsRNA (Ryter and Schultz 1998). Interestingly, leucine (L56) replaces the conserved lysine (K133) in the region 3 of DRB4-dsRBD1 (Fig. 5A, an arrowhead). Using site-directed mutagenesis, we obtained three mutant DRB4s (mDRB4s) - the H32A and K133A single substitutions and the H32A/K133A double substitution (HK).

First, we assessed the dsRNA-binding activities of the three mDRB4s in vitro. Gel-shift assays revealed that each mutation impairs the dsRNA-binding activity of the respective mutant proteins (Fig. 5B). WT reDRB4 bound to 100-bp dsRNA at a protein concentration of $25 \mathrm{nM}$ (Fig. 5B, lane 3). mDRB4:H32A showed weak dsRNA-binding activity at a protein concentration of $500 \mathrm{nM}$, but mDRB4:K133A and mDRB4:HK did not bind dsRNA even at $500 \mathrm{nM}$ (Fig. 5B, lanes 5-13), indicating that the K133A substitution affected the dsRNA-binding activity of DRB4 more severely than did the H32A substitution.

We also examined whether these mutations affected the protein-protein interaction between DRB4 and DCL4. Previously we showed that the C-terminal half of DCL4 (short DCL4; sDCL4) contains two RNase III domains and two dsRBDs and is sufficient to physically interact with DRB4 in vitro (Hiraguri et al. 2005). To test the interaction between sDCL4 and each mDRB4 protein, we performed GST-pulldown assays with GST-DRB4 or GST-mDRB4s as bait and $6 \times$ histidine tagged-sDCL4 as prey. H32A slightly impaired the DRB4/DCL4 interaction when compared to WT reDRB4 (Fig. 5C, lanes 4,5). K133A abolished the protein-protein 

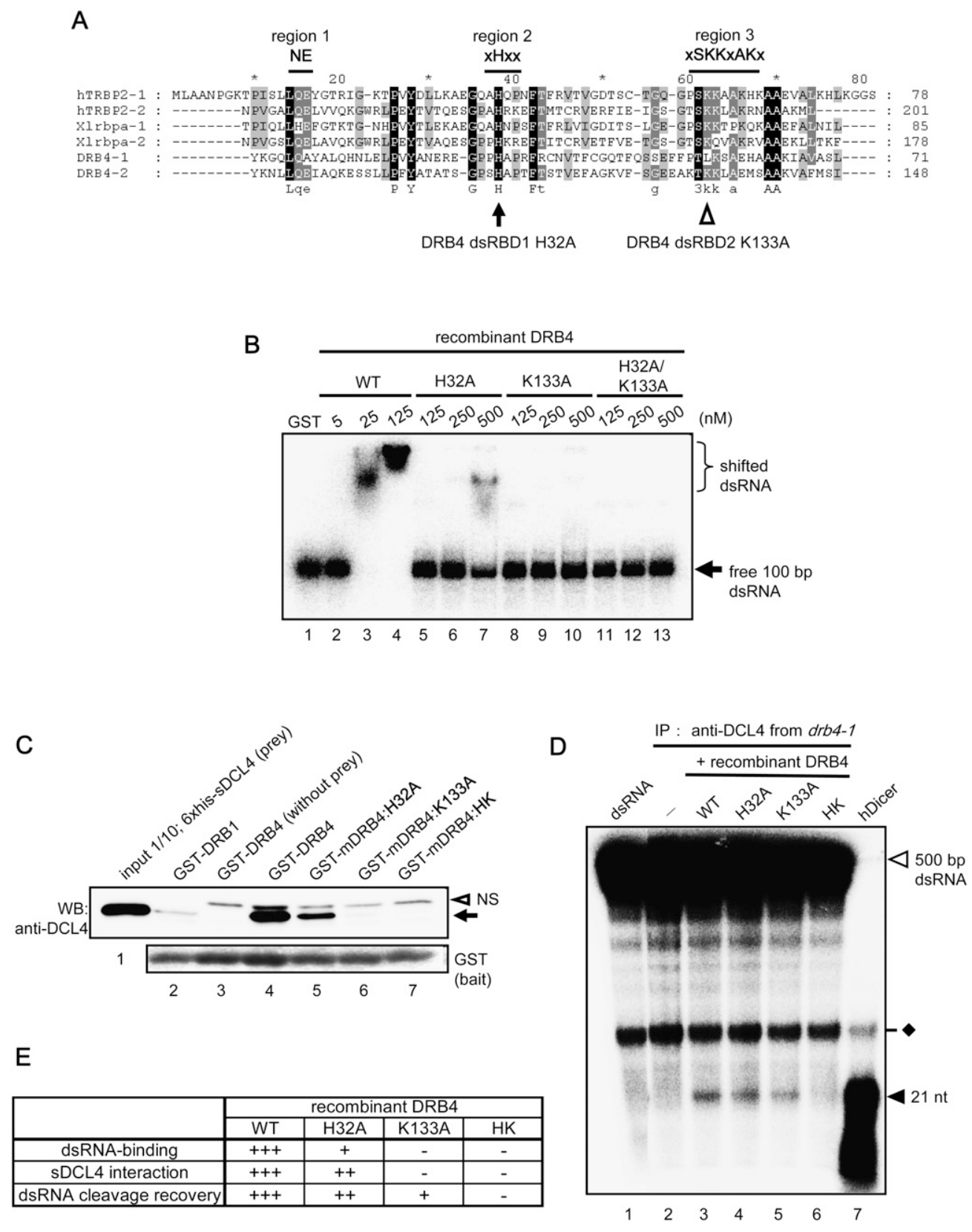

$\mathrm{E}$

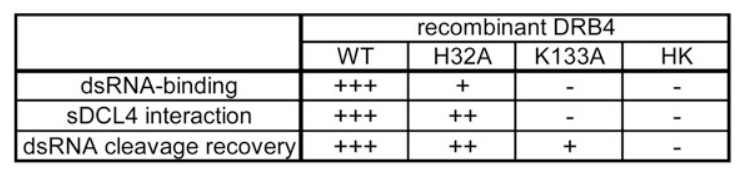

$$
\begin{array}{lllllll}
1 & 2 & 3 & 4 & 5 & 6 & 7
\end{array}
$$

FIGURE 5. Biochemical characterization of mutated DRB4s. (A) Amino acid alignment of dsRBDs. Comparisons among dsRBD1 and dsRBD2 of DRB4, hTRBP2, and Xlrbpa are shown. dsRBD consensus sequences in three conserved regions are shown (Ryter and Schultz 1998). The location of each substitution is indicated by an arrow (histidine 32, H32) and an arrowhead (lysine 133, K133). (B) Gel shift assay showing the dsRNA-binding activity of three kinds of mutated DRB4s (mDRB4; H32A, K133A, and H32A/K133A). Indicated amounts of WT and mutant DRB4 proteins were incubated with ${ }^{32}$ P-labeled 100-bp dsRNA for $30 \mathrm{~min}$ and analyzed on $6 \%$ native PAGE. (C) GST-pull-down assay demonstrating the interaction between sDCL4 and mDRB4s. About $500 \mathrm{ng}$ of GST-fused mDRB4 proteins and the same amount of $6 \times$ Histagged sDCL4 proteins were used as bait and prey, respectively. The interaction was confirmed by Western blotting using the anti-DCL4 antibody. (Arrow) Interacting $6 \times$ His-tagged sDCL4. The bands appearing above sDCL4 (an arrowhead) are non-specific (NS) signals. (HK) H32A/K133A. $(D)$ The effect of mDRB4s on the dsRNA-cleaving activity of drb4-DCL4 complexes. About $12.5 \mathrm{ng}$ of recombinant protein was used for each assay. (Black arrowhead) The 21-nt small RNAs (products). (Diamond) Short RNA fragments in dsRNA substrates (see Materials and Methods). (E) Three activities of WT reDRB4 and mDRB4s shown in $B-D$ are summarized. The number of + signs represents the relative strength of each activity, and - signs indicate that the activity was not detected.

interaction activity, as did the HK double mutation (Fig. 5C, lanes 4-7), suggesting that K133 in dsRBD2 is necessary for both dsRNA binding and the DCL4 interaction. We used GST-DRB1 as a negative control (Fig. 5C, lane 2); a weak signal indicating an interaction was detected, but the signal was as weak as non-specific signals (Fig. 5C, an arrowhead).

We also assessed ability of the three mDRB4s to rescue the 21-nt small RNA-generating activity of the drb4-DCL4 
complexes. mDRB4:H32A rescued the Dicer activity, but the rescue was weaker than the rescue associated with WT reDRB4 (Fig. 5D, lanes 3,4). Consistent with its reduced dsRNA-binding and protein-protein interaction activities, mDRB4:K133A exhibited weak rescue of the DCL4 Dicer activity (Fig. 5D, lane 5). mDRB4:HK, which lacked both the dsRNA-binding and protein-protein interaction activities, did not rescue the 21-nt small RNA generation by DCL4 (Fig. 5D, lane 6). These observations confirmed that the DRB4specific recovery of DCL4 Dicer activity observed in Figure 4 was actually due to the reDRB4 protein, not to contaminant proteins from $E$. coli. Taken together, these results suggest that both DRB4 activities, the dsRNA binding and the DCL4 interaction, were required for the function of DCL4, and the dsRBD2 region 3, where K133 is located, was essential for these activities. Figure 5E summarizes the dsRNA-binding, DCL4 interaction, and dsRNA cleavage recovery activities of each WT reDRB4 or mDRB4 protein.

\section{DISCUSSION}

The specific interactions between Dicer and a dsRBP are important to RNA silencing. A. thaliana has two major pathways: DCL1 interacts with DRB1/HYL1 facilitating proper miRNA production, and DCL4 interacts with DRB4 producing 21-nt tasiRNAs from endogenous miRNA/RDR6/ SGS3-dependent precursor dsRNAs or 21-nt siRNAs from exogenous dsRNAs such as inverted repeat transcripts from artificial transgenes or viral genome dsRNAs. Specifically, in drb4-1 mutants, exogenous 21-nt siRNAs do not accumulate; 22-nt and 24-nt siRNAs increase instead (Dunoyer et al. 2007; Curtin et al. 2008), and the endogenous tasiRNA population is slightly affected (Adenot et al. 2006; Nakazawa et al. 2007). The accumulation of TAS1 and TAS3 tasiRNAs is slightly reduced, while the TAS2 tasiRNA population seems unaffected. Therefore, the function of DRB4 in the exogenous siRNA pathway is different from its function in the endogenous tasiRNA pathway.

To determine the function of DRB4 in vitro, we biochemically characterized DCL4 activity by isolating the DCL4/ DRB4 complex. We demonstrated that DCL4 has dsRNAcleaving and 21-nt small RNA-generating activities in vitro and showed that these activities required DRB4 (Figs. 1-4). Immuno-purified DRB4 complexes and DCL4 complexes showed similar 21-nt small RNA-generating activity, and both types of complexes had biochemical properties similar to known Dicer family proteins, especially to Arabidopsis DCL1 (Figs. 2, 3; Dong et al. 2008). The DCL4 complexes immunoprecipitated from $d r b 4-1$ extracts ( $d r b 4$-DCL4 complexes) did not cleave long dsRNAs into 21-nt small RNAs (Fig. 4B). Recombinant DRB4 specifically recovered 21-nt small RNA generation by DCL4 immunoprecipitated from drb4-1 extracts, indicating that DCL4 requires DRB4 to cleave long dsRNAs into 21-nt siRNAs (Fig. 4D). This effect of DRB4 on DCL4 activity in vitro was consistent with the observation that $d r b 4-1$ abolishes 21-nt exogenous small RNA in vivo (Dunoyer et al. 2007; Curtin et al. 2008). Previously we reported that the C-terminal region of DCL4 is incapable of binding to long dsRNAs (Hiraguri et al. 2005), so one possible function of DRB4 is to bring exogenous dsRNA substrates to DCL4.

Our in vitro experiments more likely detected the DCL4/ DRB4 activity for the exogenous siRNA pathways than that for the endogenous tasiRNA pathway, because $d r b 4-1$ reduced tasiRNA accumulation only slightly in vivo (Adenot et al. 2006; Nakazawa et al. 2007). The observed requirement of DRB4 for the in vitro DCL4 activity might be specific for the exogenous siRNA generation pathway in vivo. Recently, it has been demonstrated that Drosophila Dcr-2 recruits a dsRBP Loquacious in the endogenous siRNA generation pathway while it requires R2D2 in the exogenous siRNA generation pathway (Miyoshi et al. 2010). One possibility is that DCL4 requires DRB4 in the exogenous siRNA generation pathway, which is likely to be demonstrated in this study, while it interacts with different partners for the endogenous siRNA production such as tasiRNAs. Potential candidates of co-factors of DCL4 in the tasiRNA pathway are RDR6 and SGS3, which recruit single-stranded RNAs (ssRNA) cleaved by miRNA-loaded RISC and convert them into dsRNA substrates for DCL4. Further studies for identification and characterization of other specific proteins interacting with DCL4 would reveal the molecular mechanism of how tasiRNAs are processed from their precursor dsRNAs.

In a dsRNA-cleaving assay with crude extracts from 2-wkold seedlings, a single mutation of DCL4 ( $d c l 4-2)$ was sufficient to abolish 21-nt small RNA-generating activity in vitro (Fig. 1), indicating the absence of DCL1 activity that is also known to produce 21-nt small RNAs from long dsRNA precursors. This is inconsistent with a previous biochemical study using crude extracts from inflorescence tissue (Qi et al. 2005), perhaps because of tissue or developmental stage differences. Alternatively, DCL1 activity in crude extracts from 2-wk-old seedlings might be specific for imperfect dsRNA or ssRNA containing hairpin structures. Further characterization of DCL activities in crude extracts prepared from different tissues and developmental stages and dsRNA-cleaving assays with various RNA substrates is necessary.

Another previous study shows that the accumulation of 24-nt siRNAs derived from a transgene is significantly increased in drb4-1 mutants, suggesting that DRB4 might inhibit DCL3 activity by competing for the dsRNA substrates in WT plants (Dunoyer et al. 2007). Interestingly, we did not observe increased production of 24-nt small RNAs, which DCL3 produced, in the $d r b 4-1$ crude extract (Fig. 1, lanes 2,5). This observation indicated that DRB4 may not inhibit the DCL3 activity directly.

Although specific interactions between Dicer and a dsRBP are common in various eukaryotes and dsRBPs share a similar domain structure, consisting of two N-terminal dsRBDs and one or more dsRBD or non-conserved sequence in the 
C-terminal region (Tabara et al. 2002; Hiraguri et al. 2005; Lee et al. 2006), roles of dsRBPs in these complexes are varied. On one hand, some dsRBPs play a role in the process after small RNA generation. For example, Drosophila Dicer-2 does not require a dsRBP, known as R2D2, to cleave long dsRNA, while R2D2 is essential for siRNA loading onto RISC (Liu et al. 2003, 2006). hTRBP is also known to interact with Dicer, but is not required for the dsRNAcleaving activity itself. Rather, hTRBP, like R2D2, is required for the assembly of RISC and siRNA loading onto it (Chendrimada et al. 2005). On the other hand, C. elegans Dicer requires a dsRBP known as RDE-4 to cleave dsRNA both in vitro and in vivo; cell extracts from an $r d e-4$ mutant line do not cleave dsRNA, and recombinant RDE-4 rescues the Dicer activity in these extracts (Parker et al. 2006).

In this study, we showed that the DCL4 complexes lacking DRB4 did not cleave long dsRNAs into 21-nt small RNAs (Figs. 3A, 4B). Only recombinant DRB4, not other DRB family members, specifically recovered the dsRNA-cleaving activity of $d r b 4$-DCL4 complexes in vitro (Fig. 4D). These results suggest that DRB4 plays an essential role in the dsRNA-cleaving activity of DCL4. While we could not rule out the possibility that DRB4 also affects DCL4 stability in vivo, DRB4 more likely functions in a manner similar to that of RDE-4, which is essential to the dsRNA-cleaving activity of Dicer (Parker et al. 2006), rather than that of R2D2, which has little effect on dsRNA-cleaving activity (Liu et al. 2003). In contrast, one biochemical study using recombinant proteins suggests that Arabidopsis DRB1/HYL1 facilitates the accuracy of DCL1-mediated dsRNA processing and is not required for dsRNA-cleaving activity itself in vitro (Dong et al. 2008). Another in vivo study shows that DRB1/HYL1 is involved in guide strand selection from miRNA duplexes, a process close to the loading of small RNAs into RISC (Eamens et al. 2009). Although DRB1/HYL1 and DRB4 are classified into the same dsRBP family, our results indicate that DRB4 functions are different from DRB1/HYL1 functions, which may have a role similar to those of R2D2 or hTRBP.

It is noteworthy that lysine 133 on the dsRBD2 of DRB4 seems to be essential for both the dsRNA-binding activity and the protein-protein interaction with the $\mathrm{C}$-terminal half of DCL4, suggesting that the dsRBD2 domain is critical to DRB4, enabling DCL4 to produce 21-nt small RNAs from long dsRNA (Fig. 5). Crystal structure of the second dsRBD of Xlrbpa-2 complex with dsRNA has revealed that this conserved lysine residue in region 3 resides in a loop located between $\beta$-strand 3 and $\alpha$-helix 2 , and is involved in dsRNAbinding via a direct hydrogen bond with a phosphodiester backbone of the RNA (Ryter and Schultz 1998). Since the GST-pull-down assay revealed that K133A substitution on dsRBD2 of DRB4 greatly impaired the protein-protein interaction with the C-terminal half of DCL4 (Fig. 5C), the lysine residue on DRB4 dsRBD2 might also be directly involved in protein-protein interaction. Previously we have demonstrated that the DCL4/DRB4 interaction is dsRNAindependent (Hiraguri et al. 2005), indicating that the dsRNA binding by DRB4 and the interaction between DCL4 and DRB4 occurs independently. Further structural and biochemical studies are required to determine how the single residue (K133) is involved in both dsRNA binding and protein-protein interaction. One possibility is that the K133A substitution caused a significant structural perturbation in DRB4 folding, thereby suppressing both activities.

In addition, mDRB4:HK showed much more severe deficiencies in three DRB4 activities, specifically recovery of DCL4 Dicer activity, than did mDRB4:K133A (Fig. 5B-E). This observation indicates that histidine at position 32 on the dsRBD1 is also involved in the interaction with DCL4 and facilitates its dsRNA-cleaving activity. Another report shows that DRB4 dsRBD1 specifically interacts with the DUF283 (domain of unknown function) of DCL4 (Qin et al. 2010). It is possible that DRB4 dsRBD1 interacts with DCL4-DUF283, while dsRBD2 interacts with the C-terminal region of DCL4, and these two dsRBDs cooperatively facilitate the dsRNAcleaving activity of DCL4. There may be functional specialization between dsRBD1 and dsRBD2 of DRB4; such specialization is common for many eukaryotic dsRBPs (Hiraguri et al. 2005; Laraki et al. 2008; Qin et al. 2010).

We successfully demonstrated the dsRNA-cleaving activity of DCL4 and assessed the effect of DRB4 on this activity in vitro. The experiments presented here describe a new method to analyze the biochemical features of the biologically important phenomena performed by DCL4/DRB4, that is, to biochemically characterize interactions between DCL4/DRB4 and viral suppressor proteins, and to find unknown factors regulating DCL4 activity in the tasiRNA pathway.

\section{MATERIALS AND METHODS}

\section{Plant materials and growth conditions}

Arabidopsis plants were grown on solid B5 medium in a controlledenvironment chamber under the following conditions: $40-50 \mu \mathrm{mol}$ of photons $\mathrm{m}^{-2} \mathrm{sec}^{-1}$ irradiance, $16 \mathrm{~h}$ light and $8 \mathrm{~h}$ dark, and $22^{\circ} \mathrm{C}$ after $3 \mathrm{~d}$ at $4^{\circ} \mathrm{C}$. $d c l 4-2$ (GABI $160 \mathrm{G} 05$ ) was provided by the Genomanalyse im Biologischen System Pflanze, and drb4-1 (SALK_000736) and dcl3-1 (SALK_005512) were provided by the Salk T-DNA collection. Characterization of $d c l 4-2$ and $d r b 4-1$ was previously described (Nakazawa et al. 2007).

\section{Arabidopsis extract preparation}

Two-week-old Arabidopsis seedlings were collected and homogenized in $3 \mathrm{~mL} / \mathrm{g}$ extraction buffer containing $20 \mathrm{mM}$ Tris $\mathrm{HCl}$ ( $\mathrm{pH}$ 7.5), $4 \mathrm{mM} \mathrm{MgCl}$, 5 mM DTT, $1 \mathrm{mM}$ phenyl methy sulfonyl fluoride (PMSF), $1 \mu \mathrm{g} / \mathrm{mL}$ leupeptin, and $1 \mu \mathrm{g} / \mathrm{mL}$ pepstatin A at $4^{\circ} \mathrm{C}$. Homogenates were centrifuged twice at $20,000 \mathrm{~g}$ for $10-15$ min at $4^{\circ} \mathrm{C}$ to remove debris, and the supernatant was collected as crude extract. The protein concentrations were determined by the Bio-Rad Protein Assay (Bio-Rad) and adjusted to $1.0-2.0 \mathrm{mg} / \mathrm{mL}$ with extraction buffer. 


\section{Antibodies and immunoprecipitation}

Anti-DRB4 and anti-DCL4 antiserum were described previously (Nakazawa et al. 2007). Immunoprecipitation was carried out essentially as described by Qi et al. (2005). For a standard immunoprecipitation, $1.0 \mathrm{~mL}$ of crude extract was precleared by incubation with $10 \mu \mathrm{L}$ of Protein A or Protein G Sepharose (GE Healthcare) for $30 \mathrm{~min}$ at $4^{\circ} \mathrm{C}$. Precleared extracts were then incubated with $2 \mu \mathrm{L}$ of anti-DRB4 or anti-DCL4 antiserum (proportion: 1/500) and $20 \mu \mathrm{L}$ of Protein A or Protein G Sepharose (proportion: 1/50) for $2 \mathrm{~h}$ at $4^{\circ} \mathrm{C}$ with rotation. Immunoprecipitates were washed with extraction buffer three times for 20 min each with rotation.

\section{dsRNA preparation}

$\left[\alpha-{ }^{32} \mathrm{P}\right] \mathrm{UTP}-\mathrm{labeled}$ sense and antisense transcripts were synthesized using RiboMAX T7 Large Scale RNA Production Systems (Promega) from the plasmid containing partial $(\sim 0.1 \mathrm{~kb}$ or $0.5 \mathrm{~kb})$ Arabidopsis actin gene (accession number M20016). For antisense transcripts, T3 RNA polymerases (Promega) were used instead of T7 polymerases. Equal amounts of these ${ }^{32} \mathrm{P}$-labeled RNAs were annealed in annealing buffer containing $10 \mathrm{mM}$ Tris- $\mathrm{HCl}(\mathrm{pH} 7.5)$ and $100 \mathrm{mM} \mathrm{NaCl}$ by heating for $5 \mathrm{~min}$ at $90^{\circ} \mathrm{C}$, followed by turning off a heater for $10 \mathrm{~min}$ and incubating for $10 \mathrm{~min}$ at room temperature. Template DNA and ssRNA were digested by S1 nuclease (TaKaRa) and DNase I (Promega). dsRNAs were purified by phenol/chloroform, precipitated in ethanol, and dissolved in sterilized water prior to use. Some dsRNA preparations contained short RNA fragments, which might be remnants of single-stranded RNA and are indicated as diamonds in Figures 4C and 5D and Supplemental Figure S1.

\section{dsRNA-cleaving assay}

$\left[{ }^{32} \mathrm{P}\right]$ UTP-labeled 500-bp dsRNAs (final concentration $\sim 1 \mathrm{nM}$ ) were incubated with $15 \mu \mathrm{L}$ of crude extracts or immunoprecipitates at $27^{\circ} \mathrm{C}$ with rotation for $2 \mathrm{~h}$ in dsRNA-cleaving buffer containing $30 \mathrm{mM}$ Tris- $\mathrm{HCl}$ (pH 7.5), $50 \mathrm{mM} \mathrm{NaCl}, 4 \mathrm{mM} \mathrm{MgCl}$, 5 mM ATP, and $1 \mathrm{mM}$ GTP. Additionally, $1 \mu \mathrm{L}$ of RNaseOUT (Invitrogen) was added to each $20-\mu \mathrm{L}$ reaction. After incubation, the cleavage products were purified by phenol/chloroform, separated by $15 \%$ denaturing PAGE with $8 \mathrm{M}$ urea, and detected by autoradiography. Autoradiographs are shown in Figures 1, 2A-C, 3A,B, 4B-D, and 5D. Quantification of 21-nt small RNA products (Figs. 2, 3) were calculated from relative band intensities measured with MaultiGauge software (Fuji Film).

For the dsRNA-cleaving assay with recombinant protein preparations (Fig. 4D, left panel), $\sim 25 \mathrm{ng}$ of recombinant protein was used in each assay. For combinations of immunoprecipitates and recombinant proteins (Figs. 4B-D, 5D), $15 \mu \mathrm{L}$ of immunoprecipitates was mixed with recombinant proteins, and these mixtures were incubated for $30 \mathrm{~min}$ at $4^{\circ} \mathrm{C}$ in extraction buffer prior to the dsRNA-cleaving assay described above.

\section{Site-directed mutagenesis}

The amino acid sequences of dsRBD1 and dsRBD2 in hTRBP (NP_599151), the X. laevis dsRBP Xlrbpa (Q91836), and Arabidopsis DRB4 (NP_974480) were aligned using ClustalX and GeneDoc.

pGEX-6P-2-DRB4 plasmids were mutated by the QuikChange method (Stratagene) to obtain mutant DRB4 proteins (mDRB4).
The histidine $(\mathrm{H})$ residue at position 32 (dsRBD1, region2) and the lysine $(\mathrm{K})$ residue at position 133 (dsRBD2, region3) were each substituted to an alanine (A) residue. Following primers and their reverse complements were used. For H32A, the sense primer was 5'-GAGAGAAGGGCCTCCTGCTGCTCCTAGATTTAGATG-3', and the complement primer was $5^{\prime}$-CATCTAAATCTAGGAGCAG CAGGAGGCCCTTCTCTC- ${ }^{\prime}$. For K133A, the sense primer was 5' -GGAGAAGAGGCGAAAACCGCAAAGTTGGCTGAAATGAG-3', and the complement primer was $5^{\prime}$-CTCATTTCAGCCAACTTTG CGGTTTTCGCCTCTTCTCC-3'. After whole plasmid PCR amplification with $\mathrm{Pfu}-\mathrm{X}$ polymerase (Grainer) and digestion with DpnI (TaKaRa), the PCR products were transformed into the $E$. coli DH5 $\alpha$ strain. Following overnight growth on LB agar plates containing $50 \mu \mathrm{g} / \mathrm{mL}$ ampicillin, a single colony was cultured and the plasmid DNA was extracted by alkali/SDS method and sequenced. For the H32A/K133A double mutation, the pGEX-6P2-mDRB4:K133A plasmid was further mutated using the primers for $\mathrm{H} 32 \mathrm{~A}$ substitution.

\section{Recombinant protein preparation}

For expression of the recombinant DRB family proteins and mutated DRB4 proteins, the pGEX-6P vector (GE Healthcare) was used, and proteins were purified as described previously (Hiraguri et al. 2005). The cDNA fragment of the C-terminal region of DCL4 (nucleotides 2992 to 5031 from the 5' end of the coding region) was cloned into the pCold-DNA I vector (TaKaRa) to generate $6 \times$ histidine-tagged recombinant short-DCL4 (sDCL4) proteins. For efficient protein production, the E. coli BL21 strain was co-transformed with a chaperone plasmid, pTf16 (TaKaRa), and pCold-sDCL4, and grown in the LB medium containing $50 \mu \mathrm{g} / \mathrm{mL}$ ampicillin, $20 \mu \mathrm{g} / \mathrm{mL}$ chloramphenicol, and $0.5 \mathrm{mg} / \mathrm{mL}$-arabinose. $6 \times$ his-tagged recombinant proteins were affinity-purified by $\mathrm{Ni}$ NTA resins according to the manufacturer's protocol (QIAGEN). For the dsRNA-cleaving assay and the gel-shift assay (Figs. 4A-D, 5B,D), each GST-fused protein was digested by PreScission Protease (GE Healthcare) for $4 \mathrm{~h}$ at $4^{\circ} \mathrm{C}$ with rotation to remove the GST-tag.

\section{GST-pull-down assay}

About $500 \mathrm{ng}$ of GST fusion protein (baits) was bound to Glutathione Sepharose 4B (GE healthcare) in NETN-D (50 mM Tris- $\mathrm{HCl}$ at $\mathrm{pH} 8.0,150 \mathrm{mM} \mathrm{NaCl}, 1 \mathrm{mM}$ EDTA, $1 \mathrm{mM}$ DTT, and $0.5 \% \mathrm{NP}-40$ ). After $1 \mathrm{~h}$ of incubation, the resins were washed with NETN-D twice to remove unbound proteins and incubated with the same amount of $6 \times$ His-tagged sDCL4 (prey) in NETN-D for $2-3 \mathrm{~h}$ at $4^{\circ} \mathrm{C}$ with rotation. The resins were then washed twice with NETN-D, and the bound proteins were eluted by PreScission Protease treatment for $2 \mathrm{~h}$ at $4^{\circ} \mathrm{C}$ with rotation. The eluted fraction was then analyzed by Western blotting using anti-DCL4 antibody, and interacting sDCL4 proteins were detected. The digested GSTtags bound to resins after the PreScission Protease treatment were separated by $8 \%$ SDS-PAGE, and the bands corresponding to GST were used to show the initial quantity of baits in each reaction (Fig. $5 \mathrm{C}$, lower panel).

\section{Gel-shift assay}

The $\left[{ }^{32} \mathrm{P}\right]$ UTP-labeled 100-nt dsRNAs (final concentration $\sim 5 \mathrm{nM}$ ) were incubated with recombinant proteins (final concentration 
5-500 $\mathrm{nM}$ ) for $30 \mathrm{~min}$ at $4^{\circ} \mathrm{C}$ in dsRNA-binding buffer containing $30 \mathrm{mM}$ Tris- $\mathrm{HCl}(\mathrm{pH} 7.0), 10 \mathrm{mM} \mathrm{NaCl}, 20 \mathrm{mM}$ $\mathrm{MgCl}_{2}, 0.1 \mathrm{mM}$ EDTA, and $5 \mathrm{mM}$ DTT. Reaction mixtures were separated by $6 \%$ native PAGE and analyzed by autoradiography (Fig. 5B).

\section{SUPPLEMENTAL MATERIAL}

Supplemental material is available for this article.

\section{ACKNOWLEDGMENTS}

We thank the Genomanalyse im Biologischen System Pflanze and the Arabidopsis Biological Resource Center for kindly providing the Arabidopsis seeds. This work was supported by a Grant-in-Aid for Scientific Research from the Ministry of Education, Culture, Sports, Science and Technology of Japan (No. 21580411 to T.F.), a grant from the Japan Science and Technology Agency (No. 04-143 to T.F.), and grants for protein network research from the Nara Institute of Science and Technology to A.K., Y.N., and A.H.

Received September 5, 2010; accepted December 16, 2010.

\section{REFERENCES}

Adenot X, Elmayan T, Lauressergues D, Boutet S, Bouche N, Gasciolli V, Vaucheret H. 2006. DRB4-dependent TAS3 transacting siRNAs control leaf morphology through AGO7. Curr Biol 16: 927-932.

Blevins T, Rajeswaran R, Shivaprasad PV, Beknazariants D, SiAmmour A, Park HS, Vazquez F, Robertson D, Meins F Jr, Hohn T, et al. 2006. Four plant Dicers mediate viral small RNA biogenesis and DNA virus induced silencing. Nucleic Acids Res 34: 6233-6246.

Chendrimada TP, Gregory RI, Kumaraswamy E, Norman J, Cooch N, Nishikura K, Shiekhattar R. 2005. TRBP recruits the Dicer complex to Ago 2 for microRNA processing and gene silencing. Nature 436: 740-744.

Curtin SJ, Watson JM, Smith NA, Eamens AL, Blanchard CL, Waterhouse PM. 2008. The roles of plant dsRNA-binding proteins in RNAi-like pathways. FEBS Lett 582: 2753-2760.

Deleris A, Gallego-Bartolome J, Bao J, Kasschau KD, Carrington JC, Voinnet O. 2006. Hierarchical action and inhibition of plant DICER-LIKE proteins in antiviral defence. Science 313: 68-71.

Dong Z, Han MH, Fedoroff N. 2008. The RNA-binding proteins HYL1 and SE promote accurate in vitro processing of pri-miRNA by DCL1. Proc Natl Acad Sci 105: 9970-9975.

Dunoyer P, Himber C, Voinnet O. 2005. DICER-LIKE 4 is required for RNA interference and produces $21 \mathrm{nt}$ small RNA component of the plant cell to cell signal. Nat Genet 37: 1356-1360.

Dunoyer P, Himber C, Ruiz-Ferrer V, Alioua A, Voinnet O. 2007. Intra- and intercellular RNA interference in Arabidopsis thaliana requires components of the microRNA and heterochromatic silencing pathways. Nat Genet 39: 848-856.

Eamens AL, Smith NA, Curtin SJ, Wang MB, Waterhouse PM. 2009. The Arabidopsis thaliana double-stranded RNA binding protein DRB1 directs guide strand selection from microRNA duplexes. RNA 15: 2219-2235.

Forstemann K, Tomari Y, Du T, Vagin VV, Denli AM, Bratu DP, Klattenhoff C, Theurkauf WE, Zamore PD. 2005. Normal microRNA maturation and germ-line stem cell maintenance requires
Loquacious, a double-stranded RNA-binding domain protein. PLoS Biol 3: e236. doi: 10.1371/journal.pbio.0030236.

Fusaro AF, Matthew L, Smith NA, Curtin SJ, Dedic-Hagan J, Ellacott GA, Watson JM, Wang MB, Brosnan C, Carroll BJ, et al. 2006. RNA interference-inducing hairpin RNAs in plants act through the viral defence pathway. EMBO Rep 7: 11681175 .

Haase AD, Jaskiewicz L, Zhang H, Lainé S, Sack R, Gatignol A, Filipowicz W. 2005. TRBP, a regulator of cellular PKR and HIV-1 virus expression, interacts with Dicer and functions in RNA silencing. $E M B O$ Rep 6: 961-967.

Han MH, Goud S, Song L, Fedoroff N. 2004. The Arabidopsis doublestranded protein HYL1 plays a role in microRNA-mediated gene regulation. Proc Natl Acad Sci 101: 1093-1098.

Hiraguri A, Itoh R, Kondo N, Nomura Y, Aizawa D, Murai Y, Koiwa H, Seki M, Shinozaki K, Fukuhara T. 2005. Specific interactions between Dicer-like proteins and HYL1/DRB family dsRNAbinding proteins in Arabidopsis thaliana. Plant Mol Biol 57: 173-188.

Kumakura N, Takeda A, Fujioka Y, Motose H, Watanabe Y. 2009. SGS3 and RDR6 interact and colocalize in cytoplasmic SGS3/ RDR6-bodies. FEBS Lett 583: 1261-1266.

Kurihara Y, Watanabe Y. 2004. Arabidopsis micro-RNA biogenesis through Dicer-like 1 protein functions. Proc Natl Acad Sci 101: 12753-12758.

Laraki G, Clerzius G, Daher A, Melendez-Pena C, Daniels S, Gatignol A. 2008. Interactions between the double-stranded RNA-binding proteins TRBP and PACT define the Medipal domain that mediates protein-protein interactions. RNA Biol 5: 92-103.

Lee Y, Hur I, Park SY, Kim YK, Suh MR, Kim VN. 2006. The role of PACT in the RNA silencing pathway. EMBO J 25: 522-532.

Liu Q, Rand TA, Kalidas S, Du F, Kim HE, Smith DP, Wang X. 2003. R2D2, a bridge between the initiation and effector steps of the Drosophila RNAi pathway. Science 301: 1921-1925.

Liu X, Jiang F, Kalidas S, Smith D, Liu Q. 2006. Dicer-2 and R2D2 coordinately bind siRNA to promote assembly of the siRISC complexes. RNA 12: 1514-1520.

Miyoshi K, Miyoshi T, Hartig JV, Siomi H, Siomi MC. 2010. Molecular mechanisms that funnel RNA precursors into endogenous small-interfering RNA and microRNA biogenesis pathways in Drosophila. RNA 16: 506-515.

Nakazawa Y, Hiraguri A, Moriyama H, Fukuhara T. 2007. The dsRNA-binding protein DRB4 interacts with the Dicer-like protein DCL4 in vivo and functions in the trans-acting siRNA pathway. Plant Mol Biol 63: 777-785.

Parker GS, Eckert DM, Bass BL. 2006. RDE-4 preferentially binds long dsRNA and its dimerization is necessary for cleavage of dsRNA to siRNA. RNA 12: 807-818.

Peragine A, Yoshikawa M, Wu G, Albrecht HL, Poethig RS. 2004. $S G S 3$ and $S G S 2 / S D E 1 / R D R 6$ are required for juvenile development and the production of trans-acting siRNAs in Arabidopsis. Genes Dev 18: 2368-2379.

Qi Y, Denli AM, Hannon GJ. 2005. Biochemical specialization within Arabidopsis RNA silencing pathways. Mol Cell 19: 421428.

Qin H, Chen F, Huan X, Machida S, Song J, Yuan YA. 2010. Structure of the Arabidopsis thaliana DCL4 DUF283 domain reveals a noncanonical double-stranded RNA-binding fold for protein-protein interaction. RNA 16: 474-481.

Ryter JM, Schultz SC. 1998. Molecular basis of double-stranded RNAprotein interactions; structure of a dsRNA-binding domain complexed with dsRNA. EMBO J 17: 7505-7513.

Tabara H, Yigit E, Siomi H, Mello CC. 2002. The dsRNA binding protein RDE-4 interacts with RDE-1, DCR-1, and a DExH-box helicase to direct RNAi in C. elegans. Cell 109: 861-871.

Vazquez F, Gasciolli V, Crete P, Vaucheret H. 2004a. The nuclear dsRNA binding protein HYL1 is required for microRNA 


\section{Fukudome et al.}

accumulation and plant development, but not posttranscriptional transgene silencing. Curr Biol 14: 346-351.

Vazquez F, Vaucheret H, Rajagopalan R, Lepers C, Gasciolli V, Mallory AC, Hilbert JL, Bartel DP, Crété P. 2004b. Endogenous trans-acting siRNAs regulate the accumulation of Arabidopsis mRNAs. Mol Cell 16: 69-79.

Xie Z, Johansen LK, Gustafson AM, Kasschau KD, Lellis AD, Zilberman D, Jacobsen SE, Carrington JC. 2004. Genetic and functional diversification of small RNA pathways in plants. PLoS Biol 2: e104. doi: 10.1371/journal.pbio.0020104.

Xie Z, Allen E, Wilken A, Carrington JC. 2005. DICER-LIKE 4 functions in trans-acting small interfering RNA biogenesis and vegetative phase change in Arabidopsis thaliana. Proc Natl Acad Sci 102: 12984-12989. Yoshikawa M, Peragine A, Park MY, Poethig RS. 2005. A pathway for the biogenesis of trans-acting siRNAs in Arabidopsis. Genes Dev 19: 2164-2175. 

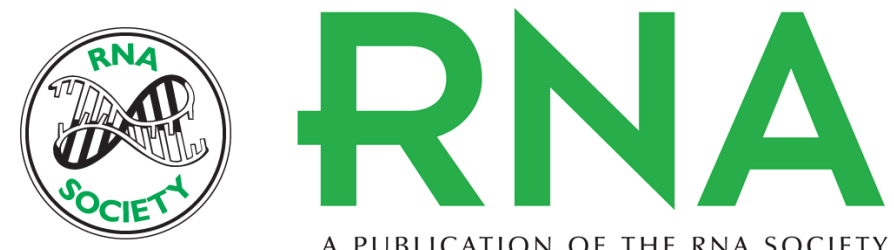

A PUBLICATION OF THE RNA SOCIETY

\section{Specific requirement of DRB4, a dsRNA-binding protein, for the in vitro dsRNA-cleaving activity of Arabidopsis Dicer-like 4}

Akihito Fukudome, Akihiro Kanaya, Mai Egami, et al.

RNA 2011 17: 750-760 originally published online January 26, 2011

Access the most recent version at doi:10.1261/rna.2455411

\section{Supplemental http://rnajournal.cshlp.org/content/suppl/2011/01/20/rna.2455411.DC1 \\ Material}

References This article cites 33 articles, 16 of which can be accessed free at: http://rnajournal.cshlp.org/content/17/4/750.full.html\#ref-list-1

\section{License}

Email Alerting Receive free email alerts when new articles cite this article - sign up in the box at the Service top right corner of the article or click here.

\section{||I||||| Providing Precise Solutions for your research.}

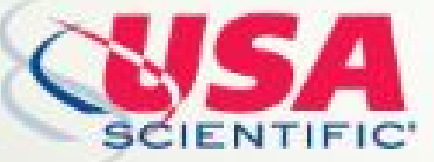

To subscribe to $R N A$ go to:

http://rnajournal.cshlp.org/subscriptions 